\title{
All-inside, suture anchor repair for meniscal root tears
}

\author{
Nam-Hong Choi · Kyoung-Mo Son • \\ Brian N. Victoroff
}

Received: 25 January 2009/Accepted: 2 February 2009/Published online: 7 March 2009

(C) Springer-Verlag 2009

\section{Dear Editor,}

We thank Dr. DiFelice et al. for their interest in our article [1] and their sincere comments. We apologize that we did not quote their article published in Skeletal Radiology [2]. We would like to congratulate them on their clinical success in the short term. There are some differences between our technique of meniscal repair and theirs. We used a posteromedial portal higher than the usual posteromedial portal to achieve the correct angle for insertion of a suture anchor. We felt that the use of a suture hook (Linvatec, Largo, FL) was easier than other instruments for passing a suture relay, and we inserted the suture hook through the anteromedial portal [they did not mention which portal was used when inserting the Viper (Arthrex, Naples, FL)].

We are very cautious in selecting patient for this procedure. We agree, as in their series, that meniscal root tears combined with multiple ligamentous injuries can be an indication for this type of repair. However, considering many medial meniscus root tears occur within the context of early osteoarthritis, indications should be considered carefully. Other contraindications would be severe displacement or degeneration of the torn edge of the meniscus from its insertion. Therefore, in patients with varus alignment and extrusion of the medial meniscus, high tibial osteotomy may be preferable to meniscal repair.

Repair of the medial meniscus root tear is a valuable technique to protect from hoop tension in the meniscus. We look forward to long-term clinical outcome results after repair of medial meniscus root tears with this technique.

\section{References}

1. Choi NH, Son KM, Victoroff BN (2008) Arthroscopic all-inside repair for a tear of posterior root of the medial meniscus: a technical note. Knee Surg Sports Traumatol Arthrosc 16:891-893

2. Engelsohn E, Umans H, DiFelice GS (2007) Marginal fractures of the medial tibial plateau: possible association with medial meniscal root tear. Skeletal Radiol 36:73-76

\author{
N.-H. Choi $(\bowtie)$ \\ Department of Orthopaedic Surgery, Eulji Medical Center, \\ 280-1, Hagye-1-dong, Nowon-gu, Seoul 139-711, Korea \\ e-mail: cnh2406@yahoo.com

\section{K.-M. Son} \\ Department of Orthopaedic Surgery, United Hospital, \\ 957-14, Dogok-dong, Gangnam-gu, \\ Seoul 135-270, South Korea \\ e-mail: comus15v@naver.com

\section{B. N. Victoroff} \\ Department of Orthopaedic Surgery, \\ Case Western Reserve University, University Hospitals, \\ 11100, Euclid Ave, Cleveland, OH 44106, USA \\ e-mail: bnvic@sbcglobal.net
}

